\title{
Development of a Novel Monolith-Bioreactor for the Treatment of VOC- polluted Air
}

Y. Jin, M. C. Veiga \& C. Kennes

Environmental Technology, Volume 27, Issue 11, 2006 , pages 1271-1277

DOI:10.1080/09593332708618744

\begin{abstract}
A novel bioreactor packed with ceramic monolith colonized by a toluene-degrading culture was investigated in order to assess its suitability for waste gas treatment. Operational parameters that were considered included start-up of the bioreactor, toluene loading rate, changes in gas flow rate, liquid feed mode, and steady-state operation. This is the first report on the treatment of toluene-polluted air in such a biological monolith reactor. Data on performance and stability have been obtained showing that this system is suitable for waste gas treatment. Removal efficiencies around $90 \%$ could be maintained at different gas flow rates, although this value gradually dropped when increasing the load above $30 \mathrm{~g} \mathrm{~m}^{-3} \mathrm{~h}^{-1}$. Interestingly, omitting the continuous feed of a liquid trickling phase improved the reactor's performance. One potential drawback that needs to be minimized is related to clogging after long term operation. Further studies aimed at optimizing this novel application would allow reaching a high performance under long-term, stable conditions.
\end{abstract}

\section{keywords}

Biofilter, mass transfer, pressure drop, toluene, waste gas. 


\section{Introduction}

Biofiltration is an established technology for air pollution control and the alternative of choice to conventional physico-chemical treatment techniques [1,2]. In recent years it has received increasing attention as a viable technology for the control of air emissions in composting facilities, municipal wastewater treatment plants, intensive stock breeding, industrial manufacturing, food and chemical industry, foundries, wood processing, surface coating and kitchens. Biofiltration is a promising technology involving the flow of a polluted air stream through a packed-bed containing microorganisms that are able to degrade pollutants into harmless products. Biofiltration is a viable and potentially cost-effective alternative for the treatment of lowconcentration polluted air streams. The low operating/energy costs result from the utilization of microbial oxidation under ambient conditions instead of oxidation by thermal or chemical means. Under the proper conditions, high removal efficiencies can be achieved and the process is environmentally friendly since the end-products are harmless or even reusable [3]. While biofiltration has emerged as an attractive technique in the treatment of waste gases, it is not completely free of problems and still needs to be further optimized. Conventional biofilters are usually packed with natural carriers, such as compost, peat or soil. They decay over time, causing compaction, clogging, short circuiting and increased headloss across the bed. In addition, using biofiltration to control hydrophobic compounds is difficult because of mass transfer rate limitations.

The monolith, which is widely used as catalyst support for gas treatment, e.g., cleaning of automotive exhaust gases and industrial off gases, can be tailored to meet the needs of a relatively inexpensive, light weight, inert, bioreactor packing that provides a high specific surface area (surface-to-volume) to greatly increase the mass transfer rate [4]. Typical monoliths consist of many parallel channels separated by thin, porous ceramic walls, representing a collection of parallel microreactors. They are formed in several configurations, usually from cordierite $(2 \mathrm{MgO} \cdot 2 \mathrm{Al} 2 \mathrm{O} 3 \cdot 5 \mathrm{SiO} 2)$ or similar silica-alumina compounds. The geometry of monolithic supports yields one major advantage over particulate packing materials since they offer very little resistance to flow.

Reactors using monolithic catalyst supports may be an attractive alternative to conventional multi-phase reactors and have been used in bioconversion and fermentation processes [4-6]. In monolithic channels bubble-train or Taylor flow usually occurs. Gas bubbles and liquid slugs move with constant velocity through the monolith channels approaching plug flow behavior. The gas is separated from the catalyst by a very thin liquid film and during their travel through the channels the liquid slugs show internal recirculation. These two properties result in optimal mass transfer.

Until now only little research has been done on its potential application in bioreactors and its suitability for biological waste gas treatment still needs to be demonstrated. The immobilization of ribonuclease A and trypsin enzymes in ceramic honeycomb monoliths was studied [7]. The ceramic monolith was utilized to immobilize glucoamylase, and demonstrated that this support was very effective for the immobilization of enzymes catalyzing the hydrolysis of high molecular weight substrates [8]. Recently it was suggested that monolith may be a promising support material for biomass because of several potential advantages [9]: (1) low pressure drop, (2) large pore size and large specific surface area, (3) thin walls, (4) better liquid distribution at low liquid flow rates, (5) high mechanical strength, and (6) scaling up promises to be relatively easy compared to other reactor types.

In this study, toluene was chosen as the target pollutant, because toluene together with other monoaromatic compounds such as benzene, ethylbenzene, and xylenes (BTEX) are commonly found in gasoline-contaminated sites and are widely used in many industrial 
processes. The presence of toluene and BTEX compounds in the environment is a major concern because of their toxicity. Besides, their high aqueous solubility, which allows them to migrate through soil and groundwater, has made them priority pollutants. The biofiltration of air streams containing toluene or related BTEX mixtures has been described previously $[1,2]$. To produce comparative results, our current work has used toluene as the sole VOC (volatile organic compound) and substrate source.

The goal of this study was to investigate the biotreatment of toluene polluted air using the novel monolith bioreactor, in which the active microorganisms are immobilized on the channel surface of the monolith. The toluene diffuses through the aqueous phase, and is biodegraded in the active biofilm. Within the framework of this research program, the suitability and performance of the novel monolith bioreactor was evaluated.

\section{Material and methods}

\section{Monolith Support}

The ceramic monolith packing is shown in Figure 1 (A) and has the following characteristics: geometry: square ducts; length: $150 \mathrm{~mm}$; cross section: $100 \mathrm{X} 100 \mathrm{~mm}$; number of channels: $26 \mathrm{X} \mathrm{26}$; channel width: $3.0 \mathrm{~mm}$; weight: $850 \mathrm{~kg} \mathrm{~m}^{-3}$; geometric surface: $800 \mathrm{~m} 2 \mathrm{~m}^{-3}$; voids fraction: $64 \%$. Details of the composition and the preparation procedure of the monolith used in this work are proprietary information of Rauschert Verfahrenstechnik GmbH (Germany).

A

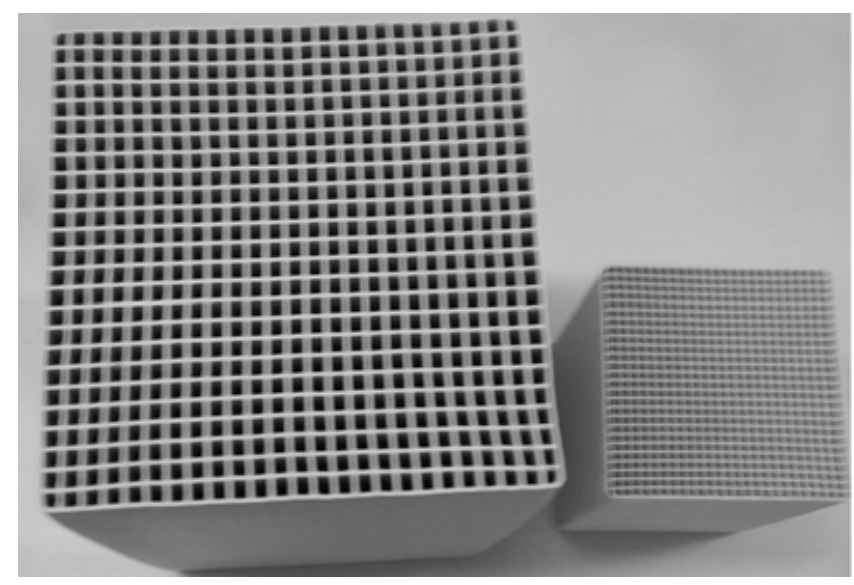




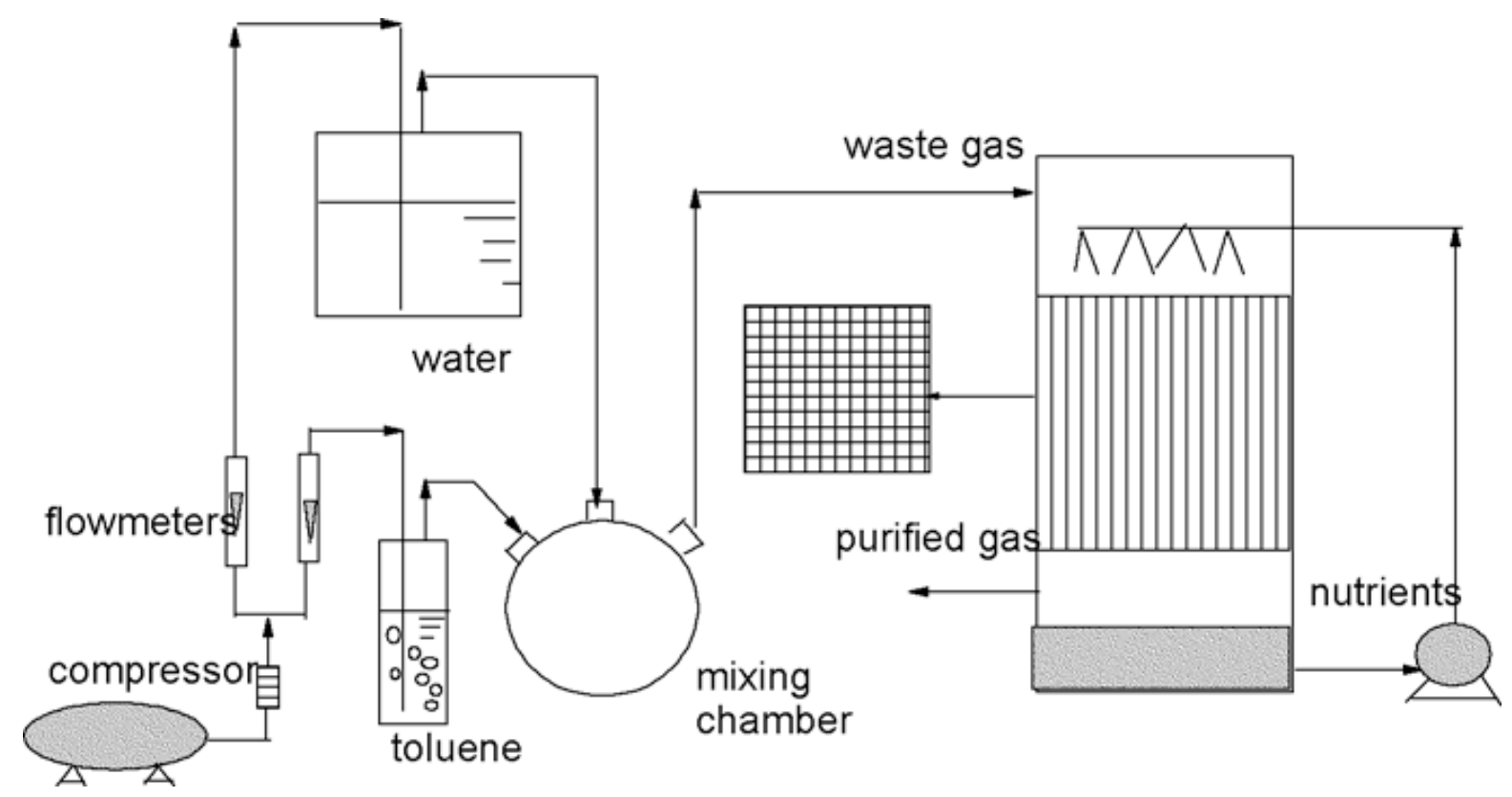

Figure 1. Monolith bioreactor. (A) Monolith packing. (B) Schematic of the monolith bioreactor.

\section{Medium Composition}

Batch experiments and growth of the inocula were undertaken with an aqueous culture medium containing (per liter): $4.5 \mathrm{~g} \mathrm{KH}_{2} \mathrm{PO}_{4}, 0.5 \mathrm{~g} \mathrm{~K}_{2} \mathrm{HPO}_{4}, 2.0 \mathrm{~g} \mathrm{NH} 4 \mathrm{Cl}$ and $0.1 \mathrm{~g}$ $\mathrm{MgSO}_{4} \cdot 7 \mathrm{H}_{2} \mathrm{O}$ [10]. The culture medium was autoclaved at $120{ }^{\circ} \mathrm{C}$ for 20 min before adding filter-sterilized solutions of vitamins and trace minerals. The composition of the vitamins solution was (per liter): $0.2 \mathrm{~g}$ thiamine. $\mathrm{HCl}, 0.1 \mathrm{~g}$ riboflavin, $1.0 \mathrm{~g}$ nicotinic acid, $2.0 \mathrm{~g} \mathrm{Ca}-$ pantothenate, $0.1 \mathrm{~g}$ biotin, $0.1 \mathrm{~g}$ thioctic acid, $0.1 \mathrm{~g}$ folic acid and $0.25 \mathrm{~g}$ pyridoxine $\mathrm{HCl}$. The composition of the trace minerals solution was (per liter): $120 \mathrm{mg} \mathrm{FeCl}, 50 \mathrm{mg} \mathrm{H}_{3} \mathrm{BO}_{3}$, $10 \mathrm{mg} \mathrm{CuSO} \cdot 5 \mathrm{H} 2 \mathrm{O}, 10 \mathrm{mg} \mathrm{KI}, 45 \mathrm{mg} \mathrm{MnSO}_{4} \cdot \mathrm{H}_{2} \mathrm{O}, 20 \mathrm{mg} \mathrm{Na} \mathrm{MoO}_{4} \cdot 2 \mathrm{H} 2 \mathrm{O}, 75 \mathrm{mg}$ $\mathrm{ZnSO}_{4} \cdot{ }_{7} \mathrm{H} 2 \mathrm{O}, 50 \mathrm{mg} \mathrm{CoCl} \cdot{ }_{2} \cdot 6 \mathrm{H} 2 \mathrm{O}, 20 \mathrm{mg} \mathrm{KAl}\left(\mathrm{SO}_{4}\right)_{2} \cdot 12 \mathrm{H}_{2} \mathrm{O}, 13.25 \mathrm{mg} \mathrm{CaCl}{ }_{2} \cdot 2 \mathrm{H}_{2} \mathrm{O}$ and $10,000 \mathrm{mg} \mathrm{NaCl}$. The initial $\mathrm{pH}$ of thatmedium was 5.9.

\section{Microorganism Inoculation}

The microbial consortium used to inoculate the bioreactor was obtained from a previous experiment in which a biofilter treating toluene polluted air was studied. Before inoculation of the bioreactor, the enrichment culture (500 ml with an optical density of 0.23 at $660 \mathrm{~nm}$ ) was diluted to $2 \mathrm{l}$ in the above mentioned medium. Toluene was added to the medium at a concentration of $4 \mathrm{ml} \mathrm{l-1}$ medium d- 1 . The monolith was placed on a metal support inside a $6 \mathrm{l}$ container with a recirculating drip system prior to the introduction into the packed column configuration. The nutrient solution was pumped from the sedimentation basin through a peristaltic pump into a distribution manifold. The sieve screen located above the monolith allows uniform nutrient distribution over the top of the monolith. After 10 days continuous recirculation of a toluene containing solution over the packing material, a visible biofilm developed on the surface of the square channels of the monolith. Afterwards, the monolith was transferred to the bioreactor and toluene-polluted air was fed continuously. 


\section{Experimental Setup}

The schematic of the bioreactor used in this study is shown in Figure 1 (B). The monolith column was placed in a plastic box. A large stream of compressed air was humidified up to $97 \%$ relative humidity by passing it through a packing tower humidified with water. A small stream of air was bubbled through a vial containing pure toluene and wasmixed with the larger humidified gas stream. Gas phase toluene concentrations ranging from 0 to $452 \mathrm{mg} \mathrm{m}^{-}$

${ }^{3}$ were obtained by changing the flow rates of the different gas streams. The resulting synthetic waste gas was introduced through the top of the column in a co-current flow. Anaqueous mineral medium was recirculated over the packed bed once per week in order to add fresh nutrients and remove the accumulated metabolites, if any. In trickling phase experiments, the flow rate of the trickling liquid was $1 \mathrm{l} \mathrm{h}^{-1}$.

\section{Analytical Methods}

The concentration of toluene in the gas phase was measured by gas chromatography using a Hewlett-Packard 5890 series II gas chromatograph (GC) equipped with a flame ionization detector (FID) (flow rates: $\mathrm{H} 230 \mathrm{ml} \mathrm{min}^{-1}$, air $300 \mathrm{ml} \mathrm{min}^{-1}$ ). The inlet and outlet streams were sampled, as well as air at different bioreactor depths. The GC was equipped with a 50 $\mathrm{m}$ TRACER column (TR-WAX, internal diameter $0.32 \mathrm{~mm}$, film thickness $1.2 \mu \mathrm{m}$ ) and Helium was used as the carrier gas (flow rate $2.0 \mathrm{ml} \mathrm{min}^{-1}$ ). The toluene concentration was determined at the oven temperature of $175{ }^{\circ} \mathrm{C}$ and the FID at $250{ }^{\circ} \mathrm{C}$. Similarly, $\mathrm{CO}_{2}$ concentration was measured using another Hewlett-Packard 5890 series II GC equipped with a thermal conductivity detector (TCD). The $\mathrm{CO}_{2}$ concentrations were determined at an injection temperature of $90{ }^{\circ} \mathrm{C}$ and an oven temperature of $25^{\circ} \mathrm{C}$ and using a TCD at $100{ }^{\circ} \mathrm{C}$. From the difference between the inlet and outlet values of a manometer connected to the inlet and outlet ports of the reactor, pressure drop was calculated and normalized per meter packing height.

\section{Results and discussion}

\section{Batch Assays}

All assays were performed at least in duplicate, with the corresponding controls. Both uninoculated media (called "blanks") and inoculated autoclaved vials (called "controls") were used. The mineral medium described above $(100 \mathrm{ml})$ was introduced into $500-\mathrm{ml}$ bottles closed with Viton septa and screw caps. Toluene was added to reach a gas-phase concentration of $3.5 \mathrm{~g} \mathrm{~m}$-3. Initially, toluene degradation and biomass growth were slow. Afterwards, the microorganisms entered the log phase and the degradation rate of toluene increased sharply (Figure 2(a)). Around 60\% of the toluene added to the vials was recovered as carbon dioxide (Figure 2(b)). This is similar as in previous laboratory studies on biodegradation of toluene [10]. When biomass growth is taken into account, 6.35 moles CO2 are generated for each mol of toluene degraded, according to the stoichiometric equation if complete degradation takes place:

$$
1.55 \mathrm{C}_{7} \mathrm{H}_{8}+12 \mathrm{O}_{2}+0.2 \mathrm{NH}_{4} \mathrm{Cl} \rightarrow \mathrm{CH}_{1.8} \mathrm{NO}_{0.5}+9.85 \mathrm{CO}_{2}+5.6 \mathrm{H}_{2} \mathrm{O}+0.2 \mathrm{HCl}
$$

Our results suggest that toluene was completely degraded, without accumulation of any intermediate metabolite. 
a)

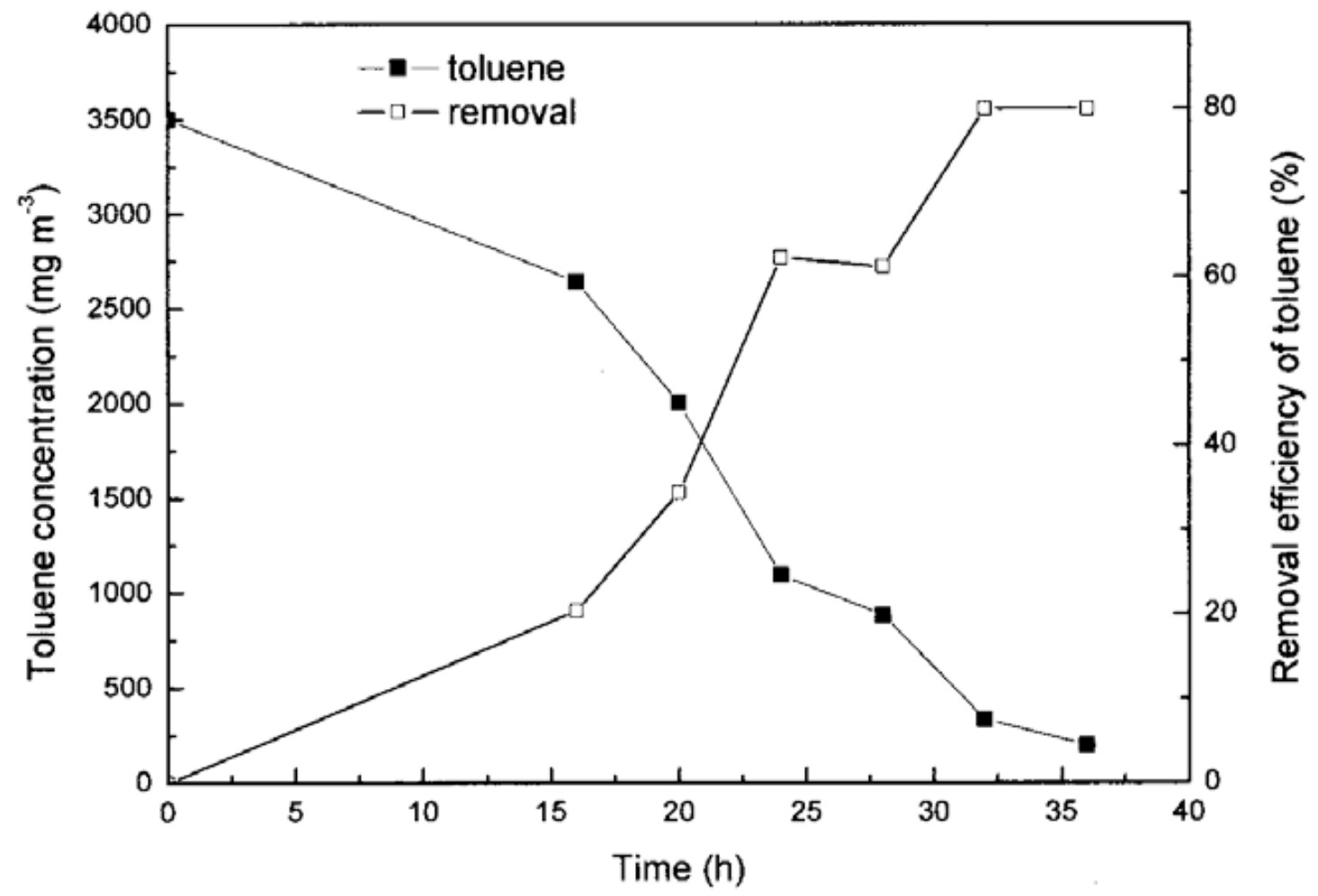

b)

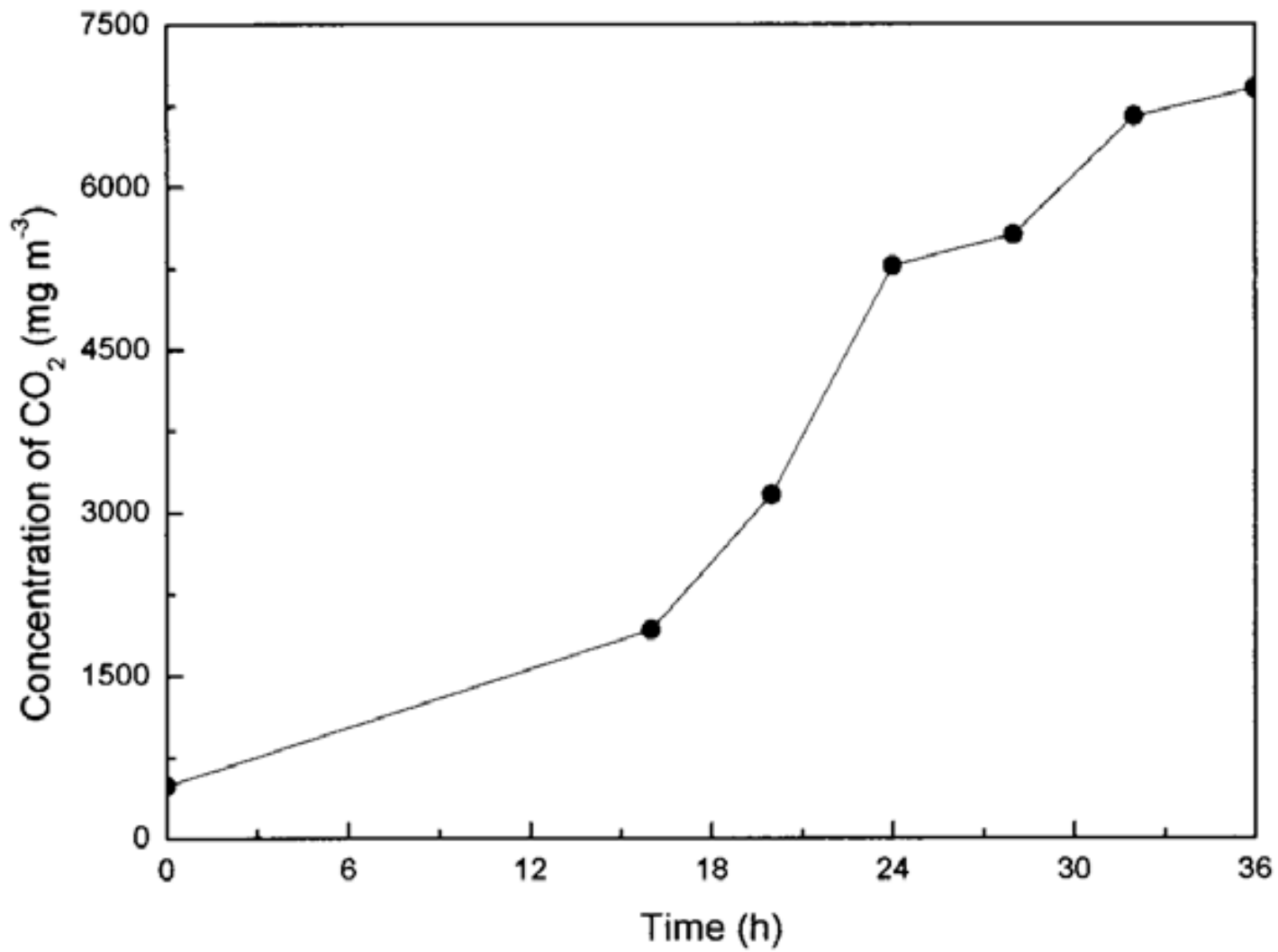

Figure 2. Batch assay of biodegradation of toluene. (a) Toluene concentration and removal efficiency. (b) CO2 concentration. 


\section{Start-Up and Performance of the Bioreactor}

The start-up period of the bioreactor lasted around 24 days with removal efficiencies of 60100\% while slowly increasing the load from 0.395 to $29.5 \mathrm{~g} \mathrm{~m}-3 \mathrm{~h}-1$. (Figure 3 (a) and (b)). These data show that the start-up phase is quite slow. After this period, the inlet concentration was kept at $376 \mathrm{mg} \mathrm{m}-3$ with an empty bed residence time (EBRT) of $68 \mathrm{~s}$, reaching an elimination capacity of $25 \mathrm{~g}$ m-3 h-1, while maintaining the removal efficiency around $80 \%$. The relationship between the loading rate and the elimination capacity as well as the removal efficiency are shown in Figure 3(b) for the complete experimental period.

\section{Effect of the Gas Flow Rate}

The influence of the gas flow rate on the reactor's performance was evaluated. In the range of gas flow rates of 18 to $110 \mathrm{l} \mathrm{h}-1$, the removal efficiency first remained constant, around $90 \%$ (Figure 4), while gradually increasing the gas flow rate. When the gas flow rate was further increased, the biofilm thickness decreased due to the shear force. The mass transfer limitation step was determined by the laminar film thickness between the gas and liquid phase. When the gas flow rate increased, the turbulence of the gas increased, and the laminar film became thinner. Hence, the resistance decreased and mass transfer was enhanced. Figure 4 shows that the highest elimination capacity was reached at the highest gas flow rate, although this led to a lower removal efficiency.

(A)

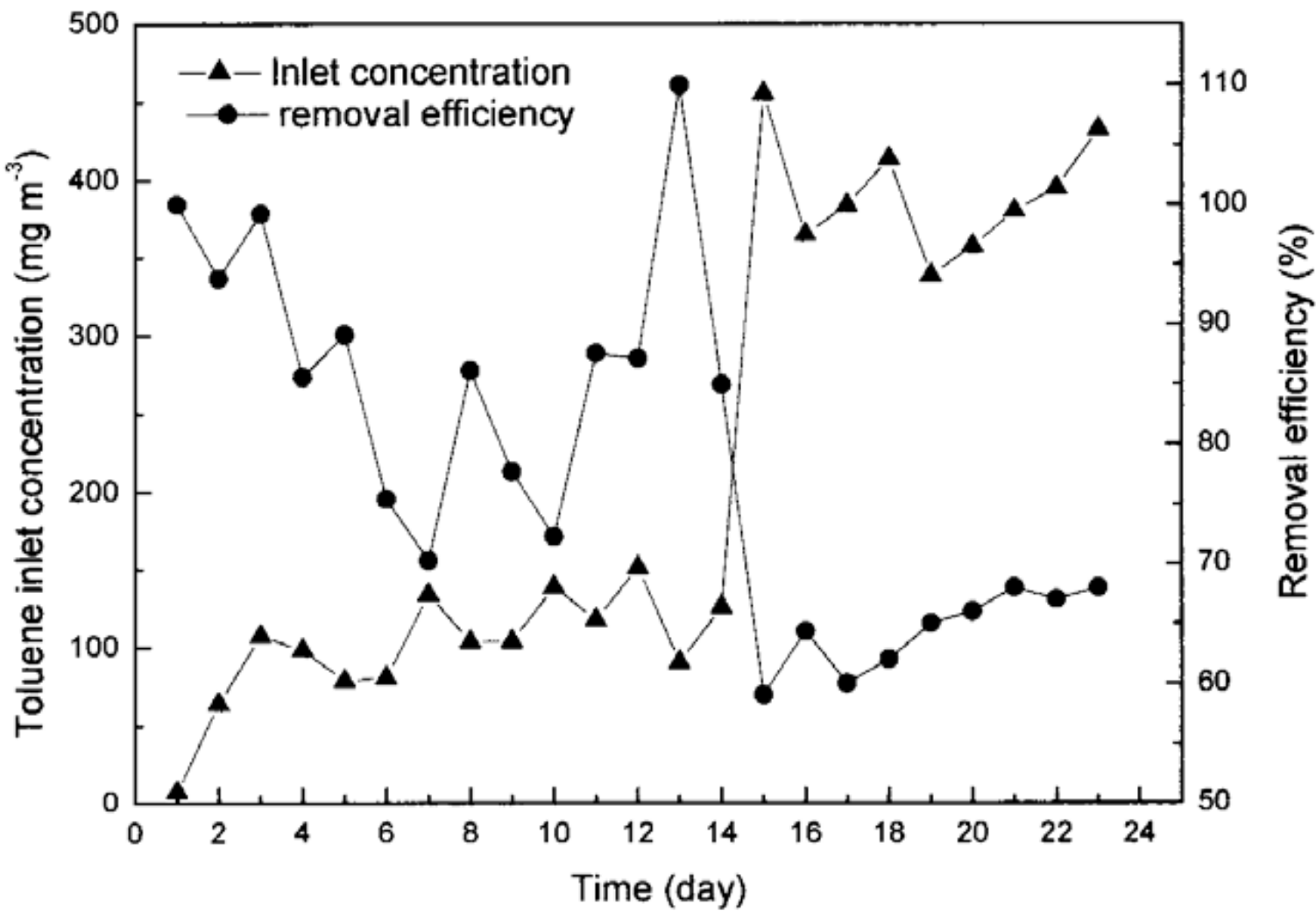


(B)

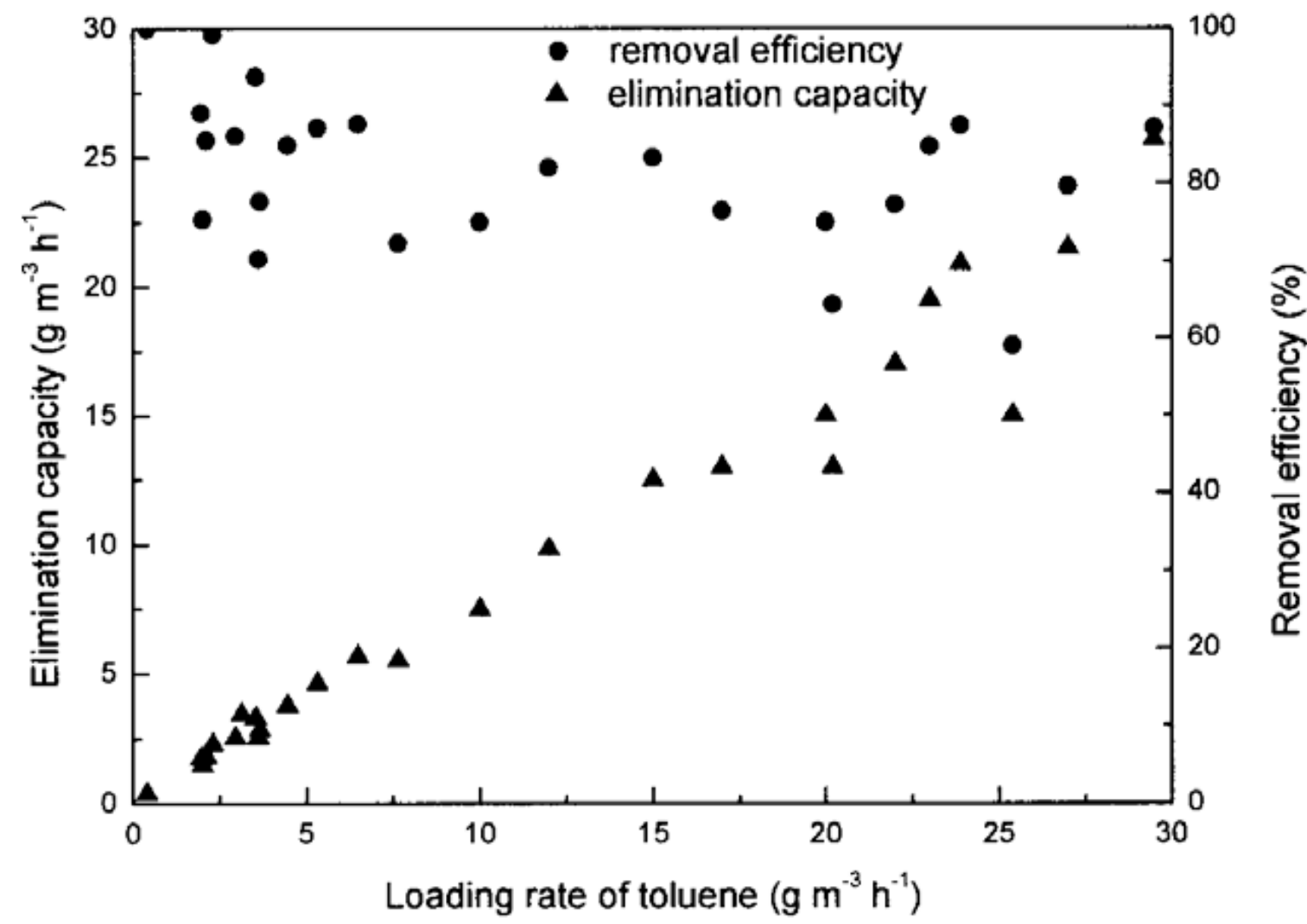

Figure 3. Start-up and performance of bioreactor. (A) Start-up of the bioreactor. (B) Performance of monolith bioreactor treating toluene.

\section{Performance With or Without Trickling Liquid Phase}

The gas and liquid mixture travels through the channels of the monolith reactor. Depending on the flow rate of each phase and on the feed method, a number of different flow regimes can occur, such as the dispersed bubble flow, bubble flow, aerated Taylor flow, Taylor flow, churn turbulent flow, slug flow, annular flow and mist flow. In the co-current downflow trickling operation, the gas and liquid phases go in the same direction through the channels. In this operation mode the Taylor flow regime is preferred. The superficial liquid and gas velocities used in this experiment correspond to the Taylor flow regime according to the flow map for cocurrent gas and liquid flows through a tube [11].

In this regime the gas and liquid move through the channels as separate packages, ensuring plug flow behavior. The gas bubbles are separated from the bio-catalytic wall, containing the attached biofilm, only by a thin liquid film. Gas adsorbed in this film can immediately be consumed by the bio-catalyst attached on the walls of the channels. Adsorbed gas that is not consumed at the film exchanges with the liquid plug. The recirculation pattern in the liquid plug facilitates a rapid exchange with the film. Because of these properties of Taylor flow in capillaries, a high gas-liquid mass transfer rate is obtained. 


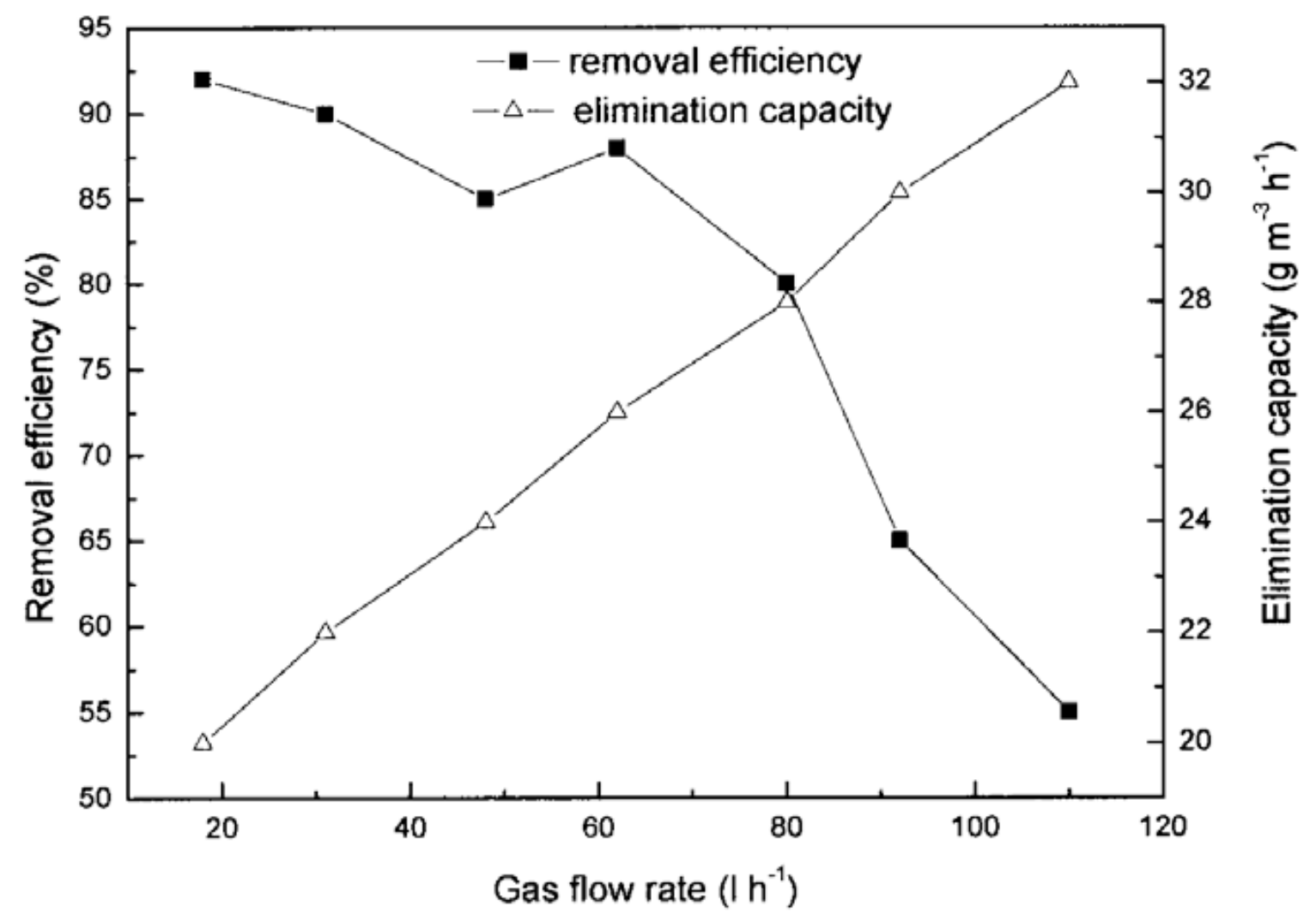

Figure 4. Effect of the gas flow rate on toluene removal.

In order to check the effect of the mode of feeding of the liquid phase, the bioreactor was first operated in a trickling mode and later without trickling phase (no recirculation of the liquid medium). The flow rate of the gas and liquid were 80 and $1 \mathrm{l} \mathrm{h}^{-1}$, respectively. The removal of toluene in the trickling mode was lower than without trickling phase in the experimental range of inlet concentrations used in this work (Figure 5). This seems to contradict the theory that Taylor flow could enhance the mass transfer from the gas phase to the liquid phase. This may be due to the following reasons: (1) when no liquid is recirculated in the reactor, the gas flow is uniform, and the liquid inside the channel forms a very thin liquid film, then the resistance between the gas phase and the liquid phase is low, (2) in the trickling mode, although the Taylor flow generated by the liquid flow could enhance the mass transfer, the liquid was not uniformly distributed in the monolith. This could cause non-homogenous mass transfer in the different channels, (3) the rather hydrophobic nature of toluene would also explain its better removal in the absence of a continuous trickling aqueous phase.

\section{Monolith Blockage}

The experiment was stopped when clogging of the monolith channels was detected. The pressure drop sharply increased from initially zero to $0.5 \mathrm{~cm}$ H2O. The biofilm growth made the gas flow and liquid flow regime become non-homogenous, and the performance of the bioreactor decreased dramatically. In order to remove excess biomass, a high flow rate of trickling liquid was used. The turbulence that was generated allowed to wash out part of the biofilm from the reactor. It seems that controlling the biofilm growth is a very important parameter for long term stable operation of monolith bioreactors. This problem could be solved by optimizing the dimensions of the channels or by means of washing with a high flow rate of the trickling liquid. Preliminary studies undertaken with smaller channels, 
characterized by a channel width of $1.27 \mathrm{~mm}$ instead of $3.0 \mathrm{~mm}$, resulted in a still faster clogging (non published data).

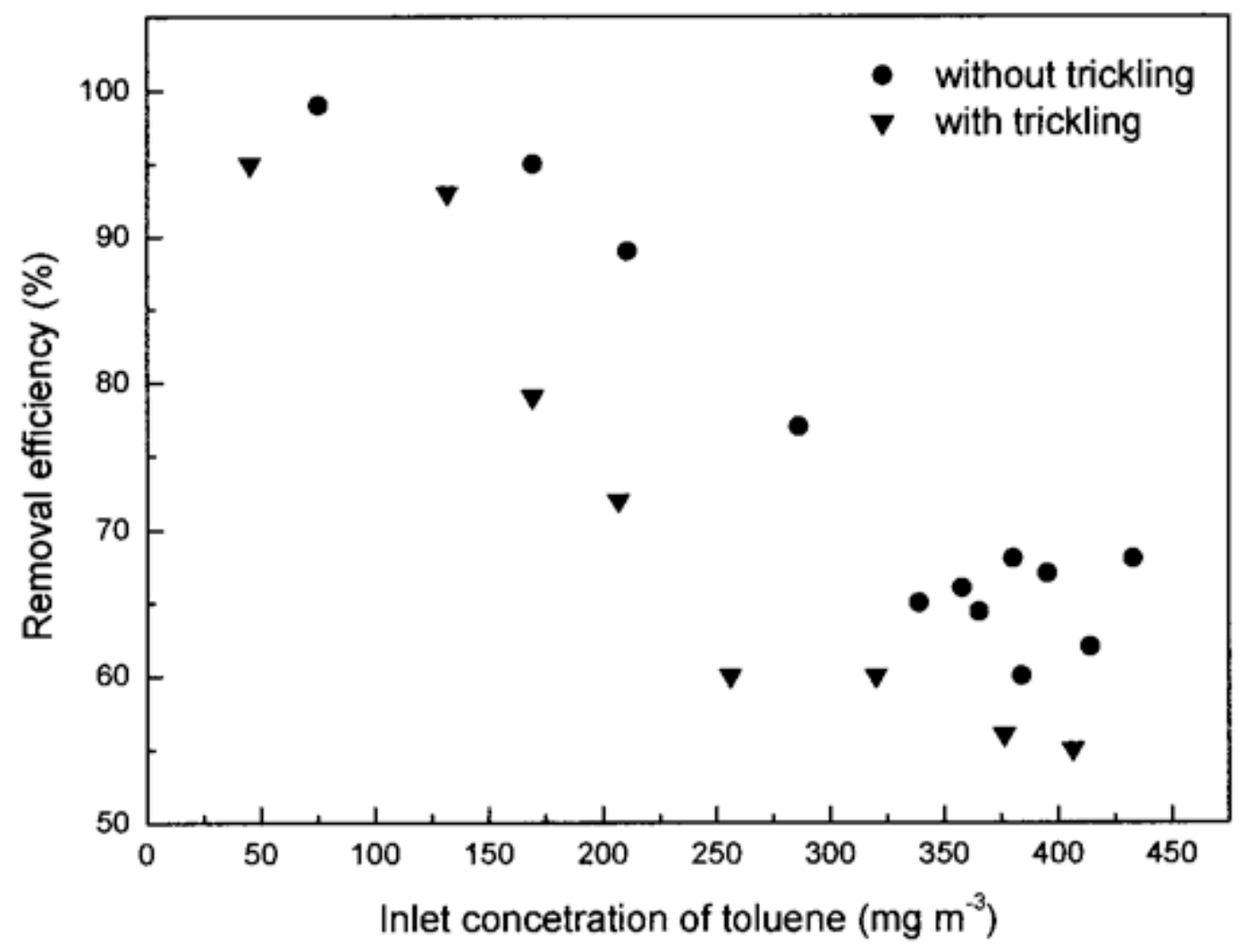

Figure 5. Performance of the monolith bioreactor with or without trickling phase.

\section{Conclusions}

The potential of the monolith bioreactor, in terms of novel applications in the field of biotreatment of waste gases was demonstrated. The system was used to biodegrade a toluene polluted air stream. The bioreactor was found to readily support biomass growth on the high surface. This provided excellent contact between the waste gas phase, liquid (biofilm) phase and solid. The results show that increasing the gas flow rate enhanced the biodegradation of toluene, although the removal efficiency gradually decreased. In addition, the bioreactor performed better when operated without trickling phase, which could result from the hydrophobic nature of the pollutant and from a reduced mass tranfer. Clogging of the channels in long term operation is a potential problem. In future work, addressing the clogging issue will be one of the main challenges. Possible solutions may consist in optimizing the size of the monolith channels, use a washing procedure or operate the bioreactor alternatively with and without trickling phase.

\section{Acknowledgements}

The present research was financed by the Spanish Ministry of Education and Science (Project CTM2004-00427) and through European FEDER funds. Yaomin Jin was financially supported through a fellowship of the Agencia Española de Cooperación Internacional (AECI) and the Ministry of Foreign Affairs. We owe special thanks to Rauschert Verfahrenstechnik GmbH, Germany, for collaborating in this study and for providing the monolith carriers. 


\section{References}

1. Kennes C. and Thalasso F., Waste gas biotreatment technology. J. Chem. Technol. Biotechnol., 72, 303-319 (1998).

2. Kennes C. and Veiga M.C., Conventional biofilters, In: Bioreactors for Waste Gas Treatment, Kennes C. and Veiga M.C. (ed.), Kluwer Academic Publishers, Dordrecht/Boston/London, pp.47-98 (2001).

3. Jin Y., Veiga M.C. and Kennes C., Effect of pH, CO2, and flow pattern on the autotrophic degradation of hydrogen sulfide in a biotrickling filter. Biotechnol. Bioeng., 92, 462-471 (2005).

4. Ariga O., Kimura M., Taya M. and Kobayashi T., Kinetic evaluation and characterization of ceramic honeycomb-monolith bioreactor. J. Ferment. Technol., 64, 327-334 (1986).

5. Kawakami K., Adachi K., Minemura N. and Kusunoki K., Characteristics of a honeycomb monolith 3-phase bioreactoroxidation of glucose by immobilized glucoseoxidase. Kagaku Kogaku Ronbunshu, 13, 318-324 (1987).

6. Kawakami K., Kawasaki K., Shiraishi F. and Kusunoki K., Performance of a honeycomb monolith bioreactor in a gas-liquid solid three-phase system. Ind. Eng. Chem. Res., 28, 394400 (1989).

7. Kirwan D.J., Enright J.T. and Gainer J.L., Enhanced enzymatic reaction rates with substrates in aerosol form. Biotechnol. Bioeng., 16, 551-553 (1974).

8. Shiraishi F., Kawakami K., Kono S., Tamura A., Tsuruta S. and Kusunoki K., Characterization of production of free gluconic acid by Gluconobacter suboxydans adsorbed on ceramic honeycomb monolith. Biotechnol. Bioeng., 33, 1413-1418 (1989).

9. Ebrahimi S., Kleerebezem R., Kreutzer M.T., Kapteijn F., Moulijn J.A., Heijnen J.J. and van Loosdrecht M.C.M., Potential application of monolith packed columns as bioreactors, control of biofilm formation. Biotechnol. Bioeng., 93, 238-245 (2006).

10. Estévez E., Veiga M.C. and Kennes C., Biofiltration of waste gases with the fungi Exophiala oligosperma and Paecilomyces variotii. Appl. Microbiol. Biotechnol., 67, 563568 (2005).

11. Kapteijn F., Heiszwolf J.J., Nijhuis T.A. and Moulijn J.A., Monoliths in multiphase catalytic processes—aspects and prospects. CATTECH, 3, 24-41 (1999). 